\title{
Research on the Phenomenon of Moral Defects in Social Media and Its Influence on People
}

\author{
Edmund Benedict Amara
}

\begin{abstract}
The unethical use of the social media in Sierra Leone is a concern amongst the citizens of the country and the international community. This publication looks at the unethical use of the social media and its effect on the people of Sierra Leone. The objective of the study is to investigate the possible causes and effects of unethical use of the social media on the people of Sierra Leone. Mode of data collection was through designed questionnaire and in some quarter, mobile phone interviews. Causes and effects were qualitatively and quantitatively analyzed. Research work shows that the media is unethically used in the following ways in Sierra Leone: spread of hate messages, spread of false news, spread of immorality, gateway for robbery and gateway for examinations malpractices. These unethical uses are seen to be caused by: Political ill intentions, high rate of illiteracy in the country, Poor media monitoring and poor media policy enforcement. The effects of these unethical uses of the social media were seen to be alarming. The spread of false news and examinations malpractices in schools and colleges were very strong. This strength undermines the wellbeing of peaceful citizens and the educational goals of the country. Spread of hate messages, immorality and robbery had strong effects that go against our moral values in the country. Recommendations were submitted to help enhance sanity in media practice in the country.
\end{abstract}

Keywords: Unethical, Social Media, Causes, Effect

\section{Introduction of the Study}

The advent of the internet has made life of interaction confortable between users by linking them through a network. As reported in the works of an international media, the social media is an important part of one's life from shopping to electronic mails, education and business tool. In addition, the social media plays a vital role in transforming people's life style. This media includes social networking sites and blogs where people can easily connect with each other.

Since the emergence of these social networking sites like Twitter and Facebook as key tools for news, journalists and their organizations have performed a high - wire act. These sites have become a day to day routine for the people. Social media has been mainly defined to refer to "the many relatively inexpensive and widely accessible electronic tools that facilitate anyone to publish and access information, collaborate on a common effort, or build relationship".

According to K. Harvey (Ed.), Social media is the term often used to refer to new forms of media that involve interactive participation. Often the development of media is divided into two different ages, the broadcast age and the interactive age. In the broadcast age, media were almost exclusively centralized where one entity - such as a radio or television station, newspaper company, or a movie production studiodistributed messages to many people. Feedback to media outlets was often indirect, delayed, and impersonal. Mediated communication between individuals typically happened on a much smaller level, usually via personal letters, telephone calls, or sometimes on a slightly larger scale through means such as photocopied family newsletters.

In Sierra Leone the use of the social media takes the form of Whatsapp, Messenger, twitter and Facebook. Of the four commonly used media, the Whatsapp and Facebook are predominantly used in this country. Both literate and illiterate use these media for communication. The voice message via the whatsapp is commonly used by the illiterate and sending of pictures and other images. There are however unethical use of these media that have prompted this write up. The write up is to investigate the causes and effect of the unethical use of the social media on the people of Sierra Leone.

\section{Objective of the Study}

Below are the objectives of the study -

- To know the causes of the unethical use of the social media

- To know the causes of the unethical use of the social media on the people of Sierra Leone

- To give possible recommendations for the study

\section{Hypothesis of the Study}

- HO - there are causes and effects of the unethical use of the social media in Sierra Leone

- H1 - there are no causes and effects of the unethical use of the social media in Sierra Leone

\section{Scope of the Study}

The study looks at the causes and effect of the unethical use of the social media in Sierra Leone.

It investigates these causes and effects and makes recommendations that will help other researchers doing similar studies to have footing for their write ups and promote women entrepreneurs in their communities.

\section{Justification of the Study}

The study is important because it will help reduce the unethical use of the social media in the country by presenting recommendations. This will promote the wellbeing of the people of Sierra Leone and the practice of good governance in the country.

\section{Research Questions}

1) What are the causes and effect of the unethical use of the social media

2) What are the effect of the unethical use of the social media 
3) Are there recommendations to minimise the unethical use of the social media in Sierra Leone.

\section{Literature Review}

\section{Meaning of Social Media}

The introduction of new social media at a faster pace makes its ecology not static. Social media platforms are frequently introduced. Some of these introduced platforms fade away with time. (Stine Lomborg 2015). This view is adopted as there are advancement in the internet technologies every day. There are new inventions as innovations are born in the field of research. Social interactions through the social media take various forms in our days. Therefore the definition of social media should not only consider old social media platforms but also the newly developed media platforms.

Social media is seen as the umbrella term used to describe social interaction between users through technology - based tools, many of which are online. The scope of this definition goes beyond the internet forums, blogs and networking sites such as Facebook, Twitter, Instagram and LinkedIn. (2019 Institute of Business ethics)

The technological based tool is the digital means that facilitates users to create and share contents of messages with the public. Social media applications are used for interactions between users. The motive of the social media is foster interactions between users. (2016 Daniel Miller).

Above definition proves to be broad as it also considers technologies like the telegraph and telephone as social media. According to Andreas Kplan 2015. A clear definition of the social media should show the follow features:

- Internet - based applications. (2010 M. Kaplan*, Michael Haenlein)

- Content is generated by users. (2015 Jonathan A. Obar and Steve Wildman)

- Service specification profiles for the site or application that are designed and maintained by the social media organization is created by users. (2015 Jonathan A. Obar and Steve Wildman)

- The development of social networks by connecting a user's profile with those of other individuals or groups. (2015 Obar, Jonanthan A)

\section{Types of Social Media}

People use different means to interact with one another or groups. They use different types of social media to connect online. (Curtis Foreman 2017). The following are examples of social media networks:

- Social networks are designed to Connect with people. Examples of these social networks are: face book twitter and LinkedIn.

- Media sharing networks shares photos, videos, and other media. Examples of this media are: Instagram, Snapchat, YouTube

- Discussion forums shares news and ideas. Examples are reddit, Quora, Digg
- Bookmarking and content curation networks Discover, save, and share new content. Examples are Pinterest, Flipboard.

- Consumer review networks-Find and review businesses. Examples: Yelp, Zomato, TripAdvisor

- Blogging and publishing networks-Publish content online. Examples: WordPress, Tumblr, Medium

- Interest - based networks-Share interests and hobbies. Examples: Goodreads, Houzz, Last. fm

- Social shopping networks - online shopping activities. Examples: Polyvore, Etsy, Fancy

- Sharing economy networks - Trade goods and services. Examples: Airbnb, Uber, Taskrabbit

- Anonymous social networks Communicate anonymously. Examples: Whisper, Ask. fm, After School.

\section{Social Media Ethics}

Carolyn Cohn relates Ethics as a concept of what is good, bad, right and wrong. It gives room to what is generally accepted and not accepted amongst people. In social media, our right way of doing things is commensurate to the way we think and our right thinking on how to power the media in the right way as we engage people in the right way.

She added that Etiquette is a code of behavior within the context of our society. In social media, the right etiquette equals doing the right way. There definitely is a right way and a wrong way to use social media. Using a social media network simply means joining a very large community. Therefore, what is best for us with regards to generally accepted principles should be practiced. It is of utmost importance to respect the boundaries of others. Aggressive targeted marketing has no place in social media. Your motivation for being a part of the community is to give others the benefit of your experience and to build relationships with other members of your community.

Carolyn reveals the three main principles of social media ethics and etiquette as -

1) Authenticity-people will respond positively if you are sincere.

2) Transparency - having hidden agendas will only count against you.

3) Communication-getting to know people as people and letting them get to know you.

Conclusively, she said that communication in an honest and open manner. Acquaintance come as a result of openness and through acquaintance, rapport is established. Truth is an ethical value that people respect. One should know that the social media as an application should be used with ethical principles. There are various abuses of the social media that hinders the social lives of users. The whatsapp and Facebook are predominantly used in Sierra Leone as social media applications. Most practices violates the ethics and etiquettes of social media. This study is designed to investigate the causes and effects of these unethical uses on the people of Sierra Leone and give possible recommendations.

\section{Problem Statement}

The social media is meant to foster the flow of communication between people in an ethical environment. 
There are unethical uses of the social media that have got causes and effects on the people of Sierra Leone.

There are reports of abuses, fraudulent practices, misinformation and misrepresentations in the country through the use of the social media. There are promoted human right abuses engineered through the social media.

Mobilization for violence is organized and executed through the use of the social media in Sierra Leone. In Sierra Leone there are social groups that undermine governance and the rule of law in the country through the use of the social media.

\section{Research Methodology}

\section{Study Area}

Sierra Leone is a country in West Africa, on the Atlantic Ocean. It's known for the white - sand beaches lining the Freetown Peninsula. The capital city, Freetown, commemorates the nation's slave - trade history with the Cotton Tree landmark and King's Yard Gate. Both were known as places of refuge for returned slaves in the 18th and 19th centuries. Nearby Bunce Island was a key departure point during the slave trade The Sierra Leone population is about 7.65 million (2018) World Bank.

\section{Population Size}

The population represents men and women affected by the unethical uses of the social media in Sierra Leone. The total population of this study is 400 people.

\section{Sample Size}

A total number of two hundred respondents are randomly selected of which there are fifty from each region.

1) Northern Province

2) Eastern Province

3) Southern Province

4) Western Area

\section{Data Collection Method}

Researcher used the following methods for data collection:

1) Primary Research: Researcher developed a questionnaire in view of the study. Also, interviews were done via mobile phone.

2) Secondary Research: The researcher used data already done by other that is, review done by other researchers.

\section{Data Analysis Method}

3) Both qualitative and quantitative method was used for data analysis. Statistical tables are used for data display and statistical methods were used for analysis

\section{Data Description}

Spread of hate messages - In this article in research gate analysethe harms caused by hate speech using Carey's (1989) contrasting transmission and ritual models of communication. Adoption of the transmission model directs the attention of courts and legislative bodies to effects of hate speech such as emotional and behavioural changes in the recipients of the speech. In contrast, the ritual model illustrates the reinforcement of racist attitudes and disparate treatment of minorities that occurs with the repetitive use of hate speech. Although the ritual model serves a heuristic function by providing courts with a framework for understanding harm caused by hate speech, its judicial adoption to determine liability for individual instances of racist or sexist communication raises troublesome First Amendment issues.

Spread of false news - The Abstract on Science Direct reveals that Sharing of fake news on social media platforms is a global concern, with research offering little insight into the motives behind such sharing. This study adopts a mixed - method approach to explore fake - news sharing behaviour. To begin with, qualitative data from 58 open - ended essays was analysed to identify six behavioural manifestations associated with sharing fake news. Thereafter, research model hypothesizing the association between these behaviours was proposed using the honeycomb framework and the third - person effect hypothesis. Age and gender were the control variables. Two data sets obtained from cross - sectional surveys with 471 and 374 social media users were utilized to test the proposed model. The study results suggest that instantaneous sharing of news for creating awareness had positive effect on sharing fake news due to lack of time and religiosity. However, authenticating news before sharing had no effect on sharing fake news due to lack of time and religiosity. The study results also suggest that social media users who engage in active corrective action are unlikely to share fake news due to lack of time. These results have significant theoretical and practical implications.

Spread of sexual immorality - Sexting entails the sending of nude, partially nude or sexually suggestive images or text typically sent from one cell phone to another; however computers may also be used. While so - called sexting can occur between adults, it is most problematic when it involves minors as it can result in not only public embarrassment, but it may also have serious legal implications (Barak, 2005).

The Spread of Rubbery - The frequency of tweets related to crime is then compared against the number of murders, the murder rate, or the level of fear of crime as recorded in surveys. Results show that, like mass media, such as newspapers, social media suffer from a strong bias towards violent or sexual crimes. Furthermore, social media messages are not highly correlated with crime. Thus, social media is shown not to be highly useful for detecting trends in crime itself, but what they do demonstrate is rather a reflection of the level of the fear of crime.

Social Media and Examination Malpractice-Chairperson of West Africa Examination Council (WAEC), Dr Evelyn Kandakai, has said the persistence of examination malpractice and its devastating effects on educational assessment and evaluation, in the sub - region have worsened with the advent of Social Media. She stated this at the Maiden Edition of the body's two - day International Summit on Examination Malpractice organized by the Board, in Lagos, tagged; 'Examination Malpractice: The Contemporary Realities and Antidotes'. Dr. Kandakai said the social ill has been a challenge for the Council, noting 
that the Board has intensified its fight against examination malpractice. "We have made frantic appeals to all stakeholders in the education sector to partner us in the fight against this scourge that is endangering the quality of academic achievements and human capital development in our sub - region. Schools, Society and WAEC are all suspects". DrKandakai described the consequences of examination malpractice on National Development as critical, adding that its effect on National Economy was destructive.

\section{Scoring Procedure}

There are five variables and forty respondents with regards the study. Each has the opportunity to select the causes and effect of the unethical use of the social media. For every reason, the score is one. Therefore the scores depend on the causes and effect of the unethical use of the social media. Also, the effects are measured as: strong - 10 and very strong - 20

\section{Findings}

Table 1: Showing the total number of observation with regards the strength of the variables under study.

\begin{tabular}{|c|c|c|}
\hline No & Variables & No. of Respondent \\
\hline 1 & Spread of hate messages & 150 \\
\hline 2 & Spread of false news & 200 \\
\hline 3 & Spread of immorality & 175 \\
\hline 4 & Gateway for robbery & 150 \\
\hline 5 & Gateway for examination malpractices & 200 \\
\hline
\end{tabular}

Field Research 2021

The above shows that the strength of false news and examination malpractice in Sierra Leone is very strong. And that of hate messages and robbery and spread of immorality also strong. The effects of these variables are shown below.

Table 2: This table shows the strength of the variables of unethical use of the social media and their relative effect on the people

\begin{tabular}{|c|c|c|c|c|}
\hline No & Unethical Use & Strength & Effect & $\begin{array}{c}\text { Effect } \\
\text { Score }\end{array}$ \\
\hline 1 & Spread of Hate Message & 150 & Strong & 1500 \\
\hline 2 & Spread of False News & 200 & Very Strong & 4000 \\
\hline 3 & Spread of Sexual Immorality & 175 & Strong & 1750 \\
\hline 4 & Gateway for Robbery & 150 & Strong & 1500 \\
\hline 5 & $\begin{array}{c}\text { Gateway for Examination } \\
\text { Malpractice }\end{array}$ & 200 & Very Strong & 4000 \\
\hline
\end{tabular}

Field Research 2020

There are effects of the unethical variables on the people of Sierra Leone. The effect of the spread of false news and examination malpractice from the social media is very strong in Sierra Leone. The spread of hate messages, sexual immorality and practice of robbery is also strong in the country. The effects are descriptively shown below:

Table 3: Describes the effects of the unethical use of the social media variables

\begin{tabular}{|c|c|l|}
\hline No & Unethical Use & Effect \\
\hline 1 & $\begin{array}{c}\text { Spread of Hate } \\
\text { Messages }\end{array}$ & $\begin{array}{l}\text { - Disunity in the community } \\
\text { C Conflict } \\
\bullet \text { Malice }\end{array}$ \\
\hline 2 & Spread of False & $\bullet$ Strikes \\
\hline
\end{tabular}

\begin{tabular}{|c|c|l|}
\hline & News & $\begin{array}{l}\text { - political unrest } \\
\text { - workplace disorder } \\
\text { - violence }\end{array}$ \\
\hline 3 & $\begin{array}{c}\text { Spread of Sexual } \\
\text { Immorality }\end{array}$ & $\begin{array}{l}\text { - Girl child abuse } \\
\text { - Early marriages } \\
\text { - School drop out }\end{array}$ \\
\hline 4 & $\begin{array}{l}\text { Gateway for } \\
\text { Robbery }\end{array}$ & $\begin{array}{l}\text { - Financial loss } \\
\text { - Business closure } \\
\text { - Family suffering }\end{array}$ \\
\hline 5 & $\begin{array}{c}\text { Gateway for } \\
\text { Examination } \\
\text { Malpractices }\end{array}$ & $\begin{array}{l}\text { - Poor Educational standards of Sierra } \\
\text { - Leoneans }\end{array}$ \\
\hline
\end{tabular}

Field Research 2021

From the table above, one can see the clear descriptions of the effects of the unethical use of the social media. This shows the social strength of the country Sierra Leone and the use the social media.

Table 4: Below shows the Causes of the unethical use of the social media in Sierra Leone

\begin{tabular}{|l|l|c|}
\hline No & Causes & Respondents \\
\hline 1 & Political Ill Intention & 200 \\
\hline 2 & Illiteracy & 200 \\
\hline 3 & Lack of Media Supervision & 180 \\
\hline 4 & Poor Media Policy Enforcement & 200 \\
\hline
\end{tabular}

Field Research 2021

From the table above the following are seen to be the causes of the unethical use of the social media in Sierra Leone:

- Political ill intention

- High level of illiteracy in the country

- Lack of Media supervision

- Poor Media Policy enforcement

\section{Discussion of Findings}

From the study above, one can relate that there is a high level of unethical use of the social media in Sierra Leone. Reasons for such unethical practices are simply the causes highlighted above. One can see that the political ill intention has cause the spread of false and hate news within the country. The Tombo Violence was as a result of the spread of the fake and hate messages via Whatsapp against the ruling Party that erupted violence within the community. All the violence acts caused within the country are as a result of the high level of illiteracy within the country and motivated by the political ill intensions of some Sierra Leoneans.

The abuses of the social media as spelt out have a very negative effect on the wellbeing of Sierra Leoneans.

\section{Conclusions}

It is relayed in the study that there is wild abuse of the social media in Sierra Leone. Such unethical practices have got causes. These causes have very negative effect on the wellbeing of the People. Some of these unethical uses have cause violence within communities in the country. There is a high rate of spread of hate messages, false news, examinations malpractices, robbery through the use of the social media. Such practices if not addressed will lead to 
future long term instability that will lead to the loss of lives and properties in the country.

\section{Recommendations}

The following are the recommendations of the study:

1) The Internet houses have a limit on the sales of SIM cards

2) That internet houses have monitor vendors of SIM cards

3) That abuses of the media policy be dealt with by the law

4) Political Parties use the social media for the benefit of citizen and should avoid inciting statements that may possibly ignite instability.

5) That social media policing be carried out regularly as a way of monitoring to react to conflicting issues that may be disturbing towards good governance.

6) That strong sensitisation be done with regards the right use of the internet

7) That Penalties be levied for unethical use of the social media

\section{References}

[1] 2015 Stine Lomborg - Meaning of Social Media SAGE Publication

[2] 2019 Institute of Business ethics - meaning of social media - Institute Publication

[3] 2016 Daniel Miller - How the world Changed - Social Media - UCL publication

[4] 2020 Matthew Hudson - Definition of Social Media The balance small business publication

[5] 2010 M. Kaplan*, Michael Haenlein - Features of a social media - business horizon

[6] 2015 Jonathan A. Obar Steve Wildman - Social Media Definition - Telecommunications Policy

[7] 2017 Curtis Foreman - Social media network types Hootuiit Publication

[8] Carolyn Cohn - Social media ethic and etiquette Compucol communication Publication

[9] Social media, definition and classes of. In K. Harvey (Ed.), (2014)

[10] Encyclopedia of social media and politics (pp.1158 1162). Thousand Oaks, CA: Sage.

[11] Social Media, definition Maxim Wolf (2018)

[12] The Social Media https: //en. wikipedia. org/wiki/Social_media

[13] Social Media impact - International Journal of Computer Applications Technology and Research Volume 5- Issue 2, 71 - 75, 2016, ISSN: - 2319-8656

[14] Abstract on Social Media https: //www.ukais. org/resources/Documents/ukais\%202018\%20proceedi ngs\%20papers/paper_4. pdf

[15] Starting small businesses https: //www.thebalancesmb. com/what - is - social - media - 2890301

[16] The Explainer on Whatsapp https: //www.webwise. ie/parents/explainer - whatsapp/

[17] Social Media Ethics and Etiquettehttps: //www.compukol. com/social - media - ethics - and etiquette/

[18] Hate speech and its harm https: //www.researchgate. net/publication/229577515_Hate_speech_and_its_har ms_A_communication_theory_perspective
[19] Sharing of fake news https: //www.sciencedirect. com/science/article/pii/S0969698920306433 